\title{
Os impactos do PAR na educação infantil do campo: um estudo exploratório
}

\author{
The impacts of PAR in children's education of the field: an exploratory study
}

\author{
Arlete Ramos dos Santos* \\ Elenice de Brito Teixeira Silva* \\ Cândida Maria Santos Daltro Alves ${ }^{* *}$
}

\section{Resumo}

O objetivo deste artigo é analisar os impactos do Plano de Ações Articuladas (PAR) ${ }^{1}$ na política de educação infantil do campo em três municípios da Bahia: Ilhéus, Itabuna e Vitória da Conquista. A política educacional brasileira nos moldes do PAR faz parte de um contexto geral que serve aos propósitos do sistema capitalista, ao adotar o modelo de gestão pública que atende mais aos interesses do mercado e representa, ao mesmo tempo, uma forte dependência dos municípios em relação às decisões do governo federal. É nesse contexto que esta pesquisa se insere, ao focalizar a educação infantil do campo nesses municípios baianos a partir das ações implementadas via pacto federativo, tendo em vista a necessária relação com as especificidades das crianças do campo e suas famílias, preconizada em diversos documentos das áreas de educação infantil e educação do campo. A pesquisa realizada foi qualitativa, de natureza exploratória, cujos instrumentos de coleta de dados foram: revisão de literatura, entrevistas semiestruturadas, questionários e análise documental. Entre os sujeitos da pesquisa, têm-se pessoas das secretarias de educação que atuam no monitoramento do PAR bem como integrantes da coordenação de escolas do campo. Os resultados apontam que algumas ações das dimensões do PAR foram implementadas nos municípios pesquisados por meio de vários programas educacionais, porém os dados evidenciaram que o pacto federativo, embora articule diferentes dimensões para o atendimento educacional, ainda não significa um avanço na cobertura do atendimento às crianças de 0 a 5 anos no campo, tampouco na consideração das especificidades das práticas educativas nessa etapa da educação.

Palavras-chave: Educação do campo. Educação infantil. Plano de Ações Articuladas. Políticas públicas.

Recebido em 18/03/2018 - Aprovado em 13/09/2018

http://dx.doi.org/10.5335/rep.v26i1.8336

Realizou pós-doutorado em Educação e Movimentos Sociais na Unesp. Doutora em Educação pela Faculdade de Educação da Universidade Federal de Minas Gerais (FAE/UFMG). Professora adjunta da Universidade Estadual de Santa Cruz (Uesc). Professora do Programa de Pós-Graduação em Educação (PPGE) da Uesc. Professora do Programa de Pós-Graduação da Universidade Estadual do Sudoeste da Bahia (Uesb). E-mail: arlerp@hotmail.com

** Doutoranda em Educação pela FAE/UFMG. Mestre em Educação pela FAE/UFMG. Professora assistente da Universidade Estadual da Bahia (Uneb). E-mail: elenteixeira@yahoo.com.br

*** Doutora em Educação pela Unicamp. Professora adjunta da Uesc. Professora do PPGE/Uesc. E-mail: candida_alves@ yahoo.com.br 


\section{Abstract}

The objective of this article is to analyze the impacts of the Articulated Actions Plan (PAR) on children's education policy in three municipalities of Bahia: Ilhéus, Itabuna and Vitória da Conquista. The Brazilian educational policy along the lines of the RAP is part of a general context that serves the purposes of the capitalist system by adopting the public management model that best serves the interests of the market and at the same time represents a strong dependence on municipalities in relation to decisions of the Federal Government. It is in this context that this research is inserted, when focusing the children's education of the countryside in these municipalities of Bahia from the actions implemented through the federative pact, considering the necessary relation with the specificities of the rural children and their families, advocated in several documents of the areas of Early Childhood Education and Field. The research was qualitative, of an exploratory nature, whose instruments of data collection were: literature review, semi-structured interviews, questionnaires and documentary analysis. Among the subjects of the research we have people from the education secretaries that work in the monitoring of the PAR, as well as members of the coordination of rural schools. The results point out that some actions of the PAR dimensions were implemented in the municipalities surveyed through various educational programs, however, the data showed that the federative pact, although it articulates different dimensions for educational care, it does not yet mean an advance in the coverage of attendance given to children from 0 to 5 years in the field, nor in the consideration of the specificities of educational practices at this stage of education.

Keywords: Field education. Child education. Plan of Articulated Actions. Public policy.

\section{Introdução}

Este artigo analisa o Plano de Ações Articuladas (PAR), especificamente os impactos dessa política educacional brasileira na educação infantil do campo em Ilhéus, Itabuna e Vitória da Conquista, na Bahia. Trata-se de uma política educacional implementada na última década pelo Estado, oriunda de um processo histórico que se inicia no século XX e continua no século XXI, com a presença marcante do Estado como regulador da economia.

Originado desde a década de 1970, em âmbito globalizado, essa premissa neoliberal priorizou a neocolonização do capital e a naturalização dos interesses capitalistas nas políticas educacionais brasileiras, nas quais predominavam os interesses privatistas da classe dominante, que ficaram evidenciados "[...] na Lei de Diretrizes e Bases da Educação Nacional n. 9.394/96, na Lei n. 9.424/96, da Emenda Constitucional n.14/96 [...], dentre outros documentos" (SILVA, 2012, p. 4), observando-se o predomínio das categorias "cidadania" e "inclusão social" difundidas pelas agências multilaterais sob o viés da solidariedade.

Desde a reforma do Estado realizada no governo de Fernando Henrique Cardoso (FHC), as políticas educacionais brasileiras têm sido orientadas como políticas sociais, visando medidas corretivas, devido ao ideário de Estado Mínimo do contexto neoliberal, implementadas na forma de ações compensatórias e solidárias, de acordo com os pressupostos da teoria social do capital defendida pelas agências multilaterais, como o Banco Mundial e a Organização de Cooperação e Desenvolvimento Econômico (OCDE). 
Tais medidas assistencialistas tiveram continuidade em 2003, no governo de Luís Inácio Lula da Silva, por meio da mesma orientação da "revolução educacional gerenciada" e da constituição de políticas educacionais paliativas, à medida que se apresentam as tensões e reivindicações sociais. De acordo com Mészáros (2011), em consonância com o sistema capitalista, qualquer ação política que se respalde na organização da teoria social do capitalismo constituir-se-á num elemento paliativo, em que os grupos desfavorecidos não sairão da condição de desigualdade, pois essas medidas não anulam nem erradicam injustiças sociais deflagradas, apenas desmobilizam ações, arrefecem direções e colocam em suspensão o caráter dos direitos fundamentais do homem como protagonista de seu processo socio-histórico, consolidando o que propõe o capital (LIMA et al., 2012).

Em atendimento a esses preceitos do capitalismo globalizado, foi criado o Plano de Metas Compromisso Todos pela Educação, um programa estratégico do Plano de Desenvolvimento da Educação (PDE), instituído pelo Decreto no 6.094, de 24 de abril de 2007, no Governo Lula, que inaugurou um novo regime de colaboração, conciliando a atuação dos entes federados sem lhes ferir a autonomia, envolvendo primordialmente a decisão política, a ação técnica e o atendimento da demanda educacional, visando à melhoria dos indicadores educacionais. Como parte do PDE, no intuito de ter maior eficiência na implementação dos resultados das políticas educacionais, surge o PAR, segundo o qual, com base em informações do site do Ministério da Educação (MEC), trata-se de "[...] um compromisso composto de vinte e oito diretrizes e consubstanciado em um plano de metas concretas e efetivas, que compartilha competências políticas, técnicas e financeiras para a execução de programas de manutenção e desenvolvimento da educação básica". ${ }^{2}$


pela Educação, como o conjunto articulado de ações, apoiado técnica ou financeiramente pelo MEC, que visa ao cumprimento das metas do compromisso e à observância das suas diretrizes (BRASIL, 2007a). Dessa forma, o Estado brasileiro tem se reestruturado para assumir uma nova função na agenda do capital, deixando de ser apenas o executor de políticas, para ser, também, controlador e avaliador. Para tanto, tem mudado sua função enquanto aparelho administrativo, ao substituir o modelo de gestão burocrática pelo modelo de gestão gerencial: “[...] com o objetivo de garantir uma estrutura organizacional mais eficiente e flexível, preocupada com o desenvolvimento e os resultados das políticas públicas, pautando-se nos exemplos de eficiência, eficácia e produtividade" (CASTRO; TERTO; BARBOSA, 2016, p. 50). De acordo com os defensores do modelo gerencial, a solução para o gerenciamento estaria no setor privado como ideal a ser seguido, sendo que a intervenção do Estado na economia e a flexibilização de sua gestão devem se pautar na redução 
de custos e de pessoal, bem como na redução de atividades exercidas pelo Estado, visando ao aumento da eficiência e da governabilidade. Acrescenta-se, ainda, como pressuposto desse modelo a equidade na prestação de serviços e a accountability. ${ }^{3}$

As políticas daí depreendidas para a garantia desse modelo de educação proposto têm abarcado todos os níveis e modalidades da educação, e, no que se refere à educação infantil, especificamente para a formação de professores, aconteceu, no período de 2009-2011, o Programa Proinfantil, para construção, melhorias na estrutura física e aquisição de mobiliários para as instituições de educação infantil, implementando o Programa Proinfância. Ainda na última década podem ser citadas as implementações do Programa Brasil Carinhoso, que surge com a defesa da ampliação da oferta de matrícula para as crianças de 0 a 48 meses, e do Programa Caminho da escola, que inclui na proposta o apoio ao transporte escolar intracampo.

Tais programas são importantes no cenário construído na interface entre a ampliação dos saberes sobre as crianças e a afirmação dos seus direitos na Política da Infância a partir do século XX. Nesse cenário, o direito à educação infantil dirige-se aos filhos de agricultores familiares, extrativistas, pescadores artesanais, ribeirinhos, assentados e acampados da reforma agrária, quilombolas, caiçaras, povos da floresta, das águas, como reconhecimento de sua diversidade populacional. Esse direito estende-se às famílias residentes no campo, de modo específico, às mulheres. A oferta de creches e pré-escolas no campo constitui um passo importante para que as mães/mulheres possam compartilhar os cuidados com seus filhos com a sociedade e o Estado e construir alternativas para sua autonomia, enfrentando as desigualdades de gênero no campo. Nesse sentido, a educação infantil no campo é direito e também necessidade das crianças e suas famílias.

A afirmação desse direito, entretanto, ainda não foi capaz de evitar o processo de invisibilidade dos bebês e crianças de 0 a 5 anos residentes em áreas rurais, inclusive na política educacional de qualidade. Dados do MEC e do Ministério do Desenvolvimento Agrário (BRASIL, 2012) apontam que as crianças de 0 a 6 anos do campo encontram-se praticamente excluídas da educação infantil, como será apresentado em outra seção deste texto. De outro modo, as áreas da educação infantil e educação do campo já construíram referências importantes para pensar as especificidades da educação das crianças residentes em áreas rurais. A socialização dos cuidados com a criança pequena no campo garante à criança o acesso à socialização com os pares em seu território de identidade, o desenvolvimento individual e coletivo, bem como a ampliação das formas de participação nas expressões culturais e nos modos de vida no campo. O processo inicial de educação, portanto, é importante para construção da ideia de pertencimento das crianças e suas famílias, além da inserção no espaço público e das tensões daí resultantes. 
Isso posto, salienta-se que, neste artigo, serão discutidos preliminarmente alguns elementos contextuais da reforma da administração realizada em âmbito educacional a partir de 1990, pautada no federalismo, bem como sua influência no contexto educacional, tendo como referência o Plano de Metas Compromisso Todos pela Educação e o PAR, como instrumentos de planejamento da educação enquanto política pública e, em especial, para a educação infantil no campo. Em seguida, discute-se sobre a metodologia e os resultados da pesquisa realizada na Bahia, no âmbito dos municípios de Ilhéus, Itabuna e Vitória da Conquista, cujo objetivo foi o de analisar o impacto das ações do PAR nos municípios investigados, utilizando como recorte a educação infantil do campo. E, finalmente, apresentam-se algumas considerações sobre a temática, no intuito de subsidiar as discussões sobre a política educacional analisada.

\section{PAR no contexto da educação infantil do campo}

Consoante com as mudanças sofridas na gestão pública brasileira, a política educacional do país adotou, a partir da década de 1990, um modelo administrativo fundamentado na Nova Gestão Pública (NGP), com o propósito de modernizá-la e torná-la cada vez mais eficiente e produtiva. Dessa maneira, a reforma educacional abarcou os níveis macro (ministérios), intermediário (secretarias estaduais e municipais de educação) e micro (escolas) dos sistemas de ensino (CABRAL NETO, 2009).

$\mathrm{Na}$ esfera federal, esse novo modelo gerencial ganha notoriedade com a criação do PDE, pelo MEC, no dia 24 de abril de 2007 (HADDAD, 2008), em regime de colaboração com os municípios, os estados e o distrito federal, cujo propósito foi o de melhorar a qualidade da educação brasileira em todos os níveis e modalidades. Nesta mesma data, foi lançado o Plano de Metas Compromisso Todos pela Educação, normatizado pelo Decreto nº 6.094 (BRASIL, 2007a), o qual, segundo Saviani (2007), constitui-se no carro-chefe do PDE, por meio do qual o governo federal estabeleceu 28 diretrizes a serem seguidas pelos municípios na elaboração do planejamento dos seus sistemas de ensino.

Por meio do PDE, o MEC vem promovendo uma reorientação no cumprimento da sua função redistributiva e supletiva no que se refere à assistência técnica e financeira aos estados, aos municípios e ao distrito federal. Seus eixos principais, estabelecidos por meio do Decreto $\mathrm{n}^{\circ}$ 6.094, de 24 de abril de 2007, são: o Plano de Metas Compromisso Todos pela Educação, o Índice de Desenvolvimento da Educação Básica (Ideb) e o PAR. O PDE estabelece um novo padrão de relacionamento institucional do MEC com os entes federativos, o que, nas palavras do ministro da 
educação, Fernando Haddad, “[...] inaugura um novo regime de colaboração" entre os sistemas de ensino (2008, p. 05). Com efeito, a execução desse plano promove alterações substantivas na gestão educacional e escolar e promove o que ficou denominado de relações intergovernamentais (RIGs). O efeito mais perceptível das alterações promovidas pelo PDE no relacionamento do MEC com os entes federativos reside no condicionamento de todas as transferências voluntárias da União aos estados e municípios, mediante a adesão ao Compromisso Todos pela Educação.

Nesse sentido, os entes federados receberam o convite para fazer a adesão ao Plano de Metas, mediante a assinatura de um termo de adesão "voluntária", no qual se estabelece uma parceria com a União, por meio da assinatura de convênio, e a União fica incumbida de prestar assistência técnica e financeira aos estados e municípios. Vale ressaltar que a referida assistência técnica não se trata de uma "bondade" do governo federal direcionada para os municípios, uma vez que esta, de acordo com o artigo 211, da Constituição de 1988 (BRASIL, 1988), é de competência da União para com a educação básica. Tais convênios fazem parte do modelo de NGP, configuram-se como contratos de gestão e estabelecem como metas os índices de desempenho, alinhados com o financiamento da educação. Nesse sentido:

[...] esta adesão, apesar de voluntária, trata-se de um instrumento de subordinação dos estados, municípios e distrito federal à União, tendo em vista a dependência destes em relação à distribuição de recursos financeiros, bem como à prestação de contas à União. É importante destacar que as metas estabelecidas o Plano de Metas, foram determinadas pela União, sem consulta aos demais entes da federação, que perderam, de certa forma, a condição de protagonistas do processo (CASTRO; TERTO; BARBOSA, 2016, p. 66).

Depois da assinatura do termo de adesão, cada ente federado assume o compromisso de elaborar um diagnóstico sobre a situação da sua rede de ensino e, com base nesses dados, elaborar o PAR, criado pelo Decreto $\mathrm{n}^{\circ}$ 6.094/2007, artigo 9ª o qual se trata de "[...] um conjunto articulado de ações, apoiado técnica e financeiramente pelo Ministério da Educação, que visa ao cumprimento das Metas do Compromisso e a observância de suas diretrizes" (BRASIL, 2007a, não paginado). Seus beneficiários são as secretarias estaduais e municipais de educação.

O diagnóstico da realidade educacional elaborado pelos estados e municípios está estruturado em quatro grandes dimensões, como demonstra o Quadro 1. 
Quadro 1 - Dimensões do PAR

\begin{tabular}{|c|c|}
\hline \multicolumn{2}{|r|}{ DIMENSÃO 1 - Gestão Educacional } \\
\hline Área 1 & Gestão democrática: Articulação e desenvolvimento do Sistema de Ensino; \\
\hline Área 2 & $\begin{array}{l}\text { Desenvolvimento da Educação Básica: ações que visem à sua universalização, à melhoria } \\
\text { da qualidade do ensino e da aprendizagem, assegurando a equidade nas condições de } \\
\text { acesso e permanência e conclusão na idade adequada; }\end{array}$ \\
\hline Área 3 & Comunicação com a Sociedade; \\
\hline Área 4 & Suficiência e estabelecimento da equipe escolar; \\
\hline Área 5 & Gestão financeira. \\
\hline \multicolumn{2}{|r|}{ DIMENSÃO 2: Formação de Professores e de Profissionais de Serviços e Apoio Escolar } \\
\hline Área 1 & Formação inicial de Professores da Educação Básica; \\
\hline Área 2 & Formação continuada de Professo \\
\hline Área 3 & $\begin{array}{l}\text { Formação de Professores da Educação Básica para a atuação em educação especial, } \\
\text { escolas do campo, comunidades Quilombolas ou Indígenas; }\end{array}$ \\
\hline Área 4 & Formação inicial e continuada de Professores da Educação Básica para cumprimento da \\
\hline Área 5 & $\begin{array}{l}\text { Lei n 10.639/2003; } \\
\text { Formação de Profissionais da Educação (funcionários). }\end{array}$ \\
\hline \multicolumn{2}{|r|}{ DIMENSÃO 3: Práticas Pedagógicas e Avaliação } \\
\hline Área 1 & organização das práticas pedagógicas; \\
\hline Área 2 & $\begin{array}{l}\text { Avaliação da aprendizagem dos alunos e tempo para assistência individual/coletiva aos } \\
\text { alunos que apresentam dificuldade de aprendizagem. }\end{array}$ \\
\hline \multicolumn{2}{|r|}{ DIMENSÃO 4: Infraestrutura Física e Recursos Pedagógicos } \\
\hline Área 1 & Instalações físicas gerais; \\
\hline Área 2 & $\begin{array}{l}\text { Integração e expansão do uso de Tecnologias da Informação e Comunicação na } \\
\text { Educação Pública; }\end{array}$ \\
\hline Área 3 & $\begin{array}{l}\text { Recursos pedagógicos para o desenvolvimento de práticas pedagógicas que considere } \\
\text { a diversidade das demandas educacionais. }\end{array}$ \\
\hline
\end{tabular}

Fonte: Silva e Cruz (2015, p. 7).

O momento seguinte à elaboração é a análise do plano pela equipe técnica do MEC, então, se for aprovado pelos técnicos, procede-se a assinatura do Termo de Cooperação entre a União e o município. Só depois dessa ação é que os recursos são liberados. O monitoramento e o acompanhamento das ações do PAR são de responsabilidade de um comitê local, composto de representantes da sociedade civil, do Ministério Público, do Conselho Tutelar e dirigentes da educação pública, entre outros.

Neste texto, trata-se sobre as ações do PAR sobre a educação infantil nas escolas do campo em três municípios baianos, que serão contextualizados a seguir. No âmbito federativo, a educação infantil só foi reconhecida como política educacional no contexto do Estado brasileiro na Lei no 9.394/1996 - LDB -, que destaca, no artigo 29: "[...] a educação infantil, primeira etapa da educação básica, tem como 
finalidade o desenvolvimento integral da criança até seis anos de idade, em seus aspectos físico, psicológico, intelectual e social, completando a ação da família e da comunidade" (BRASIL, 1996, não paginado).

A área de educação infantil, no entanto, reconhece que a Constituição de 1988 é considerada um marco no reconhecimento da educação como direito de todas as famílias, o que gerou a prerrogativa da inclusão das crianças menores de 7 anos no sistema educacional brasileiro. Pode-se dizer que a inserção da educação infantil no conjunto das políticas educacionais, desde 1996, desencadeou um conjunto de dispositivos legais e a elaboração de parâmetros nacionais de qualidade, de infraestrutura, de referências curriculares e de formação de profissionais para atuação em creches e pré-escolas.

As conquistas na área da educação infantil, no entanto, são recentes, mas ocorreram a partir da articulação entre política, pesquisa e mobilização da sociedade civil organizada, sobretudo dos movimentos pró-creche liderados por mulheres, na perspectiva da garantia dos direitos de crianças e famílias e na afirmação de uma identidade própria das instituições e da forma de atendimento, pautada na defesa do cuidado/educação.

Os movimentos de luta pela creche, de outro lado, estiveram organizados de modo contundente em capitais brasileiras e grandes centros industriais, numa clara associação da necessidade de atendimento aos filhos de trabalhadores das metrópoles. Ainda hoje, observa-se que as vagas para os bebês ( 0 a 18 meses) nos berçários, por exemplo, estão concentradas nesses centros urbanos industriais, ao passo que muitas cidades pequenas, localizadas principalmente no interior dos estados, começaram a atender crianças de 2 anos de idade só nos últimos quatro anos.

Se as conquistas na área de educação infantil, no que se refere à oferta de matrícula e ao atendimento aos Parâmetros Nacionais de Qualidade para a Educação Infantil (BRASIL, 2006b), são recentes, como esta articulação tem sido feita na modalidade de educação infantil do campo? Observa-se que, na LDB (BRASIL, 1996), também pode ser identificado o marco da Educação do Campo na agenda política e na política educacional. O artigo 28 admite a possível adequação do currículo e de metodologias apropriadas ao meio rural, bem como a flexibilização e a organização escolar por meio da adequação do calendário escolar, para atender às condições climáticas de cada região. Com base nesse contexto, as políticas públicas educacionais vistas como direito, voltadas para a Educação do Campo, começam a tomar fôlego no cenário nacional, a partir da década de 1990.

Desde a sua gênese até o momento atual, verifica-se a existência de uma legislação que versa sobre as conquistas para a educação dos povos do campo, que 
reconhecem e legitimam seus anseios, levando em consideração as suas especificidades, como as Diretrizes Operacionais para a Educação Básica do Campo, as Resoluções no 1/2002 e nº 2/2008 do Conselho Nacional de Educação (CNE) e da Câmara de Educação Básica (CEB), a Resolução no 4, de 13 de julho de 2010 (BRASIL, 2010b), que reconhece a educação do campo como modalidade específica e define a identidade da escola do campo, o Decreto $\mathrm{n}^{\mathrm{o}}$ 7.352, de 04 de novembro de 2010, que dispõe sobre a Política Nacional de Educação do Campo e sobre o Programa Nacional de Educação na Reforma Agrária (Pronera) (BRASIL, 2010a), a Portaria no 83, de 28 de fevereiro de 2013, que institui o Programa Nacional de Educação do Campo - Pronacampo, dentre outras. Essas são legislações que orientam e normatizam a educação do campo, intermediadas por seus sistemas de ensino estaduais e municipais de ensino. No que se refere às ações do PAR, alguns programas específicos para o campo são: Programa Escola Ativa, Programa Projovem Campo Saberes da Terra, Programa Escola da Terra, PDDE Campo, PDDE Escola Sustentável, dentre outros. É importante salientar que o PAR contempla ações em todos os níveis e modalidades da educação.

As Diretrizes Curriculares Nacionais para a Educação Infantil (BRASIL, 2009), aprovadas pelo CNE em 2009 (Parecer CNE/CEB no 20/2009 e Resolução $\mathrm{CNE} / \mathrm{CEB} \mathrm{n}^{\circ}$ 5/2009), apontam, pela primeira vez na legislação da área, a necessidade de elaboração de propostas pedagógicas específicas para as crianças do campo. $\mathrm{O}$ artigo $3^{\circ}$ enfatiza uma série de princípios a serem considerados nas propostas dirigidas às crianças filhas de agricultores familiares, extrativistas, pescadores artesanais, ribeirinhos, assentados e acampados da reforma agrária, quilombolas, caiçaras e povos da floresta. No texto, consta que as propostas deverão:

I - Reconhecer os modos próprios de vida no campo como fundamentais para a constituição da identidade das crianças moradoras em territórios rurais;

II - Ter vinculação inerente à realidade dessas populações, suas culturas, tradições e identidades, assim como a práticas ambientalmente sustentáveis;

III - Flexibilizar, se necessário, calendário, rotinas e atividades respeitando as diferenças quanto à atividade econômica dessas populações;

IV - Valorizar e evidenciar os saberes e o papel dessas populações na produção de conhecimentos sobre o mundo e sobre o ambiente natural;

$\mathrm{V}$ - Prever a oferta de brinquedos e equipamentos que respeitem as características ambientais e socioculturais da comunidade (BRASIL, 2009, não paginado).

Esse documento dialoga com as Diretrizes Operacionais para a Educação Básica nas Escolas do Campo (Resolução CNE/CEB no 1, de 03 de abril de 2002), no sentido de dispor sobre a articulação da proposta educativa com a promoção da ligação territorial dos povos do campo com o espaço onde vivem e produzem seus recursos, além da efetivação das trocas de saberes e valores simbólicos atre- 
lados às suas vivências. Dialoga, ainda, com Resolução no ${ }^{2}$, de 28 de abril de 2008 (BRASIL, 2008), que estabelece diretrizes complementares, normas e princípios para o desenvolvimento de políticas públicas de atendimento da educação básica do campo, especificamente sobre a vinculação da prática educativa com manifestações culturais, tradições e identidades da população do campo, e a adequação do calendário escolar ao cronograma de atividades socioeconômicas desses povos e aos possíveis agravos climáticos, como enchentes e secas.

Embora seja possível reconhecer o avanço na consideração da especificidade da educação infantil do campo nas diretrizes e o diálogo com documentos da área de educação do campo e movimentos sociais, algumas críticas foram construídas por pesquisadoras da educação infantil acerca das categorias utilizadas para expressar o modo de vida da população do campo. Rosemberg e Artes (2012) questionam se esses "processos políticos identitários" de pais e mães trabalhadores do campo dão conta de expressar os processos construídos pelos filhos, que poderiam ou não se identificar nesses termos utilizados, como povos da floresta, por exemplo. Segundo as autoras:

A intenção aqui não é a de criticar as conceituações de povos ou comunidades tradicionais, da floresta ou do campo. A intenção aqui é apontar a necessidade de se adotarem categorias descritivas capazes de incluir a maior diversidade e abrangência possível das crianças que residem no campo ou em área rural (2012, p. 24).

Apesar dos dispositivos legais e da atenção às especificidades das crianças do campo na política nacional de educação infantil a partir de 2009, parece que há muitas dificuldades na implantação de creches e pré-escolas no campo, associadas, em alguns casos, à ideia de uma população pequena de crianças de 0 a 5 anos nas comunidades. Esses pontos possibilitam reflexões em torno de como o campo é visto e da forma como a política de educação infantil do campo tem sido implementada nos municípios brasileiros a partir da afirmação legal da articulação com os saberes locais.

Dessa forma, neste texto, pretende-se responder aos seguintes questionamentos: de que modo a educação infantil do campo foi pensada no PAR dos municípios de Ilhéus, Itabuna e Vitória da Conquista? Pode-se dizer que houve impactos dessa política na oferta e na qualidade dessa modalidade educativa nesses municípios? Esta pesquisa pretendeu analisar esses pontos, ainda que de forma exploratória.

\section{Aspectos metodológicos da pesquisa}

O método utilizado foi baseado no materialismo dialético de Marx (1982) e a metodologia foi qualitativa de caráter exploratório, visando à obtenção de resultados mais concisos e esclarecedores das questões que conduziram a esta pesquisa. 
Segundo Bogdan e Biklen (1982), essa metodologia envolve a obtenção de dados descritivos, obtidos no contato direto do pesquisador com a situação estudada, enfatiza mais o processo do que o produto e se preocupa em retratar as questões relacionadas à escola.

Inicialmente, foram realizadas revisões de literatura e documental das políticas públicas que estão sendo implementadas nos municípios investigados, observando quais os objetivos e os pressupostos teóricos que as fundamentam e como estão estruturadas nas instâncias federal, estadual e municipal. Para verificar o resultado obtido com a implementação das políticas educacionais do PAR, tanto do ponto de vista das secretarias municipais como na visão dos sujeitos da comunidade escolar, foram realizadas entrevistas semiestruturadas com diretores, coordenadores e professores, no intuito de coletar dados sobre o funcionamento das políticas públicas nas escolas municipais. Vale ressaltar que utilizamos nomes fictícios tanto para os entrevistados como para as unidades de ensino, como forma de preservar a identidade dos sujeitos da pesquisa.

$\mathrm{Na}$ coleta de dados, foram aplicados 44 questionários com questões abertas e fechadas em cada município, para professores das escolas do campo, que atuaram como sujeitos da pesquisa. Para análise dos dados, tem-se como referência a metodologia dialética, visto que "[...] a dialética é o pensamento crítico que se propõe a compreender a 'coisa em si' e sistematicamente se pergunta como é possível chegar à compreensão da realidade" (KOSIK, 1997, p. 20). Salienta-se que, neste texto, apresenta-se apenas uma parte dos dados analisados.

\section{Situando o contexto da pesquisa}

Segundo dados do Instituto Brasileiro de Geografia e Estatística (IBGE) (2010), a Bahia alcançou 14 milhões de habitantes em 2010, sendo a maior população do Nordeste e o quarto estado mais populoso no Brasil (perdendo apenas para São Paulo, Minas Gerais e Rio de Janeiro). A população baiana representa $26,4 \%$ da população nordestina e 7,3\% da população brasileira. Os 14 milhões de habitantes estão distribuídos em 417 municípios. Somente a capital, Salvador, concentra 2,6 milhões de habitantes, o que corresponde a $19 \%$ da população baiana. Em seguida, os municípios mais populosos são Feira de Santana, com 556,6 mil habitantes (4\%), e Vitória da Conquista, com 306 mil habitantes (2,2\%). Dentre os municípios baianos, destacam-se, para a coleta de dados, Ilhéus, Itabuna e Vitória da Conquista, municípios que são objetos desta pesquisa no que se refere às ações do PAR. 
O município de Ilhéus se encontra inserido no tradicional território produtor de cacau e tem uma população de 184.236 habitantes (IBGE, 2010); desse contingente, $84,28 \%$ (155.281 pessoas) residem no meio urbano e $15,72 \%$ (28.955 pessoas), no campo.

Já Itabuna está localizado no sul do estado da Bahia, sendo a quinta cidade mais populosa do estado, com uma população estimada, em 2016, de 220.386 habitantes (IBGE, 2010). De acordo com o Censo 2010, a população urbana era de 199.668 mil habitantes (98\%) e a população do campo, de 5.042 mil habitantes (2\%), o que indica grande êxodo rural nas últimas décadas. A cidade de Itabuna, em conjunto com o município vizinho de Ilhéus, forma uma aglomeração urbana classificada pelo IBGE como uma capital regional B, exercendo influência em mais de 40 municípios, que, juntos, apresentam pouco mais de um milhão de habitantes.

O município de Vitória da Conquista, localizado no sudoeste da Bahia, possuía 336.987 habitantes, em 2013, de acordo com estimativa realizada pelo IBGE. A divisão entre população residente na cidade e no campo é do Censo 2010 e contabiliza $90 \%$ (274.805 mil habitantes) do total populacional concentrado na cidade e $10 \%$, no campo (31.569 mil habitantes).

Desse modo, a escolha por esses três municípios se justifica pela posição que ocupam no estado em relação ao quantitativo populacional.

Em se tratando da quantidade de instituições de educação infantil e de crianças de 0 a 5 anos matriculadas nos municípios pesquisados, observa-se que o município de Ilhéus tem conseguido manter certa estabilidade nos indicadores, conforme Tabela 1.

Tabela 1 - Dados de matrícula na educação infantil em llhéus - 2015-2017

\begin{tabular}{l|c|c|c|c|c|c|}
\cline { 2 - 7 } & \multicolumn{2}{|c|}{2015} & \multicolumn{2}{c|}{2016} & \multicolumn{2}{c}{2017} \\
\hline Área & Campo & Cidade & Campo & Cidade & Campo & Cidade \\
No de matrículas & 4.645 & 14.521 & 4.610 & 14.831 & 4.942 & 15.444 \\
Quantidade de creches & 0 & 1 & 0 & 1 & 0 & 1 \\
Quantidade de escolas que & 13 & 21 & 13 & 21 & 13 & 18 \\
oferecem educação infantil & 0 & 0 & 0 & 0 & 0 & 0 \\
\hline No de creches de Proinfância & 0 & 0
\end{tabular}

Fonte: elaboração das autoras a partir de dados fornecidos pela Secretaria Municipal de Educação de Ilhéus, BA, 2017.

Apesar da ligeira queda na matrícula da educação infantil no campo no ano de 2016, observa-se que houve uma recuperação no ano seguinte. Em contraposição, as matrículas nas instituições localizadas na cidade diminuíram de 2016 para 2017. Outro dado interessante refere-se à quantidade de creches e escolas que oferecem educação infantil no campo. Enquanto o município dispõe de apenas 
1 creche no campo, 13 escolas de ensino fundamental atendem também às crianças de 3 a 5 anos de idade. Isso demonstra que o atendimento às crianças de 0 a 3 anos, sobretudo no campo, está longe de cumprir a meta do Plano Nacional de Educação (PNE), que estabeleceu a ampliação dessa oferta em até 50\% no período de vigência do plano. De acordo com o Observatório do PNE (BRASIL, 2017), apenas 88 crianças de 0 a 3 anos foram matriculadas em creche no campo neste município no ano de 2016. Em 2010, o Censo demográfico do IBGE, conforme organização do Movimento Todos pela Educação, apontava que, em toda a rede, as matrículas de crianças de 0 a 3 na cidade e no campo atingiam o percentual de 19,3\%.

Na plataforma do Sistema Integrado de Monitoramento, Execução e Controle (Simec), ${ }^{4}$ no PAR do município, consta que Ilhéus foi contemplada com seis creches-escola em 2009, sendo que três projetos foram aprovados em 2011. No site da prefeitura do município, em 2012, noticiou-se que o governo municipal teria cadastrado quatro terrenos nos bairros Banco da Vitória, Teotônio Vilela, Malhado e na Avenida Esperança, que atenderiam aos requisitos estabelecidos pelo programa Proinfância, tendo em vista a construção dos espaços. Entretanto, até o ano de 2017, nenhuma instituição de educação infantil foi construída ou equipada com recurso do Proinfância no município, algo que merece análises posteriores.

No município de Itabuna, os dados apresentados na Tabela 2 apontam para uma realidade que vem se tornando constante nos municípios brasileiros em relação à redução de matrículas na educação do campo, de modo geral, e na educação infantil. Observa-se, desde 2013, um acentuado fechamento de escolas do campo em Itabuna. Das 31 escolas do campo, 7 foram fechadas, passando para 25 escolas em 2014 e 2015. Em 2016, mais uma escola foi fechada, restando apenas 24 . O fechamento das escolas do campo é proibido de acordo com a Lei $\mathrm{n}^{\mathrm{o}} 12.960$, de 27 de março de 2014, que: "Altera a Lei no 9.394, de 20 de dezembro de 1996, que estabelece as diretrizes e bases da educação nacional, para fazer constar a exigência de manifestação de órgão normativo do sistema de ensino para o fechamento de escolas do campo, indígenas e quilombolas” (BRASIL, 2014, não paginado).

Tabela 2 - Dados de matrícula na educação infantil em Itabuna - 2015-2017

\begin{tabular}{l|c|c|c|c|c|c}
\cline { 2 - 7 } & \multicolumn{2}{c|}{2015} & \multicolumn{2}{c|}{2016} & \multicolumn{2}{c}{$2017^{*}$} \\
\hline Área & Campo & Cidade & Campo & Cidade & Campo & Cidade \\
$N^{\circ}$ de matrículas & 669 & 18.040 & 560 & 16.752 & 439 & 17.324 \\
Quantidade de creches & 0 & 10 & 0 & 10 & 0 & 10 \\
Quantidade de escolas que & 12 & 45 & 11 & 44 & 11 & 44 \\
oferecem educação infantil & & & & & & \\
$N^{\circ}$ de creches de Proinfância & 0 & 01 & 0 & 01 & 0 & 01
\end{tabular}

Fonte: elaboração das autoras a partir de dados fornecidos pela Secretaria Municipal de Educação de Itabuna, BA, 2017.

*Os dados de 2017 constam no Observatório do PNE (BRASIL, 2017). 
A redução no número de matrículas, comparando os dados dos últimos três anos, fornecidos pela Secretaria Municipal de Educação e registrados pelo Observatório do PNE, aponta para o fechamento de 230 vagas para crianças de 0 a 5 anos no campo e uma escola que oferecia vaga para a educação infantil no campo. Uma questão que chama a atenção no caso de Itabuna é a inexistência de instituições específicas para a educação infantil no campo, algo que também se repete na maioria dos municípios baianos. De acordo com o Observatório do PNE (BRASIL, 2017), nenhuma matrícula para crianças de 0 a 3 anos foi efetivada na educação infantil do campo neste município. Conclui-se que apenas a oferta obrigatória (para crianças de 4 e 5 anos) está disponível em algumas escolas de ensino fundamental do campo, sem atendimento aos Parâmetros Básicos de Infraestrutura para Instituições de Educação Infantil (BRASIL, 2006a).

De acordo com a coordenadora da educação do campo do município de Itabuna, as condições dos espaços não atendem às especificidades das crianças e, entende-se, também, das práticas educativas na educação infantil. Nas suas palavras:

São três escolas que se pode dizer que têm uma estrutura adequada. São escolas que são dentro de uma casa, passado por alguma reforma, que possui banheiro, que possui cozinha; mas duas dessas, das outras escolas, não é uma estrutura adequada para funcionar uma escola, porque falta água encanada, faltam banheiros, cozinha adequadas. A gente não tem pias, lava prato no chão. A gente não tem água, tem que pegar da chuva ou tem que pedir para alguém da comunidade trazer a água. Outras não têm banheiro, a gente utiliza uma instalação que fica quase uns cinquenta metros da escola. Então, duas estão em estado precário, funcionam em baixo de uma barcaça, mas é o que a gente tem (Coordenação da educação do campo do município de Itabuna, entrevista em 2016).

Fica evidente, na narrativa da coordenadora, uma preocupação com o atendimento às crianças da educação infantil, que ocorre na mesma sala com crianças do $1^{\circ}$ ao $5^{\circ}$ ano. O professor dessa etapa também recebe formação abrangente para dar conta da educação infantil aos anos iniciais do ensino fundamental e é responsável por fazer a merenda das crianças. O que se constata na análise da entrevista da coordenação de educação do campo é que apesar dos programas de formação de professores de educação infantil, vinculados ao PAR, como o Proinfantil, muitos professores da educação infantil do campo no município participaram do Escola Ativa, com ênfase na educação do campo e com abrangência das outras etapas da educação básica.

Os dados relativos ao município de Vitória da Conquista indicam leve oscilação no número de crianças (de 3 a 5 anos) matriculadas na educação infantil do campo nos três últimos anos, conforme Tabela 3. Entretanto, quando observados os dados da última década, percebe-se que o fenômeno da redução não se repetiu. 
Tabela 3 - Dados de matrícula na educação infantil em Vitória da Conquista - 2015-2017

\begin{tabular}{l|c|c|c|c|c|c}
\cline { 2 - 7 } & \multicolumn{2}{|c|}{2015} & \multicolumn{2}{c|}{2016} & \multicolumn{2}{c}{2017} \\
\hline Área & Campo & Cidade & Campo & Cidade & Campo & Cidade \\
$N^{\circ}$ de matrículas & 1.438 & 5.222 & 1.414 & 5.647 & 1.440 & 6.782 \\
Quantidade de creches & 01 & 22 & 01 & 23 & 01 & 27 \\
Quantidade de escolas que & 0 & 0 & 0 & 0 & 0 & 0 \\
oferecem educação infantil & & & & & & \\
$N^{\circ}$ de creches de Proinfância & 0 & 0 & 0 & 5 & 0 & 5 \\
\hline
\end{tabular}

Fonte: elaboração das autoras a partir de dados fornecidos pela Secretaria Municipal de Educação de Vitória da Conquista, BA (2017).

Os dados do Observatório do PNE (BRASIL, 2017) indicam que, entre 2007 e 2016, o aumento da matrícula no campo foi, em média, de $3 \%$ anual, sobretudo se consideradas as matrículas na pré-escola. Isso pode estar relacionado com a obrigatoriedade da matrícula das crianças de 4 e 5 anos, após Emenda Constitucional $n^{\circ} 59$, de 2009. Embora a cidade registre um número significativo de creches, inclusive do Proinfância, no campo, apenas escolas de ensino fundamental incluem atendimento às crianças de 4 e 5 anos. Até o ano de 2014, eram 29 dessas escolas, não sendo possível afirmar a quantidade que permanece em 2017.

Ao analisar os documentos que versam sobre os contratos de adesão entre os municípios investigados e o governo federal, no que diz respeito a Vitória da Conquista, foram detectados alguns termos de compromisso do PAR, ainda em vigor, que fazem atendimento à educação infantil, conforme Quadro 1, a saber: a) TC PAR 201500033: referente à compra de mobiliário escolar, eletrônicos da linha branca, no valor de $\mathrm{R} \$ 740.917,28$; b) TC PAR 4777: referente à compra de ônibus, projetor e mobiliário, no valor total de $\mathrm{R} \$ 2.541 .100,00$; c) TC PAR 9237: referente à compra de utensílio de cozinha, no valor total de $\mathrm{R} \$ 892.804,25$.

Essa ação compreende a Dimensão 1, na Área 2 do PAR, conforme explicita $o$ Quadro 1: "Desenvolvimento da Educação Básica: ações que visem a sua universalização, à melhoria da qualidade do ensino e da aprendizagem assegurando a equidade nas condições de acesso e permanência e conclusão na idade adequada". Já o programa que diz respeito à aquisição de mobiliários e equipamentos escolares está implícito na Dimensão 4, "Infraestrutura Física e Recursos Pedagógicos"; por fim, o "Programa Brasil Carinhoso" está relacionado a várias dimensões, uma vez que contempla o cuidado integral da criança, o que exige ações de gestão, formação e instalações físicas.

Foram firmados também termos de compromisso entre os governos municipais e o governo federal para a construção de creches infantis Proinfância. No site do MEC, ${ }^{5}$ há informações sobre a construção de creches por meio do Programa 
Nacional de Reestruturação e Aquisição de Equipamentos para a Rede Escolar Pública de Educação Infantil (Proinfância) e a de construção e a cobertura de quadras esportivas com recursos previstos no Programa de Aceleração do Crescimento (PAC 2). Entretanto, nesta pesquisa, ficou evidenciado que, em Vitória da Conquista, nenhuma creche está em localidade reconhecida como zona rural. Entretanto, duas localidades, identificadas como Lagoa das Flores e Povoado de Simão, atendem, predominantemente, comunidades rurais. Nos demais municípios, os dados também não evidenciaram nenhuma creche na zona rural.

No caso de Vitória da Conquista, a técnica do PAR no município destaca, na entrevista, que, mesmo com os Programas Brasil Carinhoso e Proinfância, não fora construída nenhuma instituição no campo. É possível compreender, a partir da entrevista da técnica, que esta questão tem a ver com a baixa procura de creches pelas famílias do campo.

Quando você vai fazer (uma creche), você não só coloca assim: "vou fazer uma creche e está bom". Você tem que se informar se tem o terreno, mandar planta, mandar informações que você tem, se realmente naquele terreno você pode construir e que você tenha também a demanda do aluno, porque também não adianta você construir uma creche "num" lugar que não vai ter demanda de aluno (Técnica do PAR, entrevista em 2016).

Essa ideia de "baixa procura por creche" é algo que também pode ser observado em outros municípios pequenos do interior dos estados, incluindo cidade e campo, o que pode conduzir a alguns questionamentos:

a) a política de educação infantil, especificamente de atendimento em creche (crianças de 0 a 3 anos e 11 meses), seria ainda focalizada na lógica de amparo às crianças para as mães que trabalham "fora de casa"?

b) no caso das cidades pequenas do interior dos estados, em que geralmente não há transporte coletivo, seriam as famílias, então, responsáveis pelas crianças enquanto as mães trabalham "fora de casa"? E as famílias do campo, como elas têm resolvido a questão do trabalho e do cuidado com os filhos?

c) a obrigatoriedade da matrícula de crianças de 4 e 5 anos e, consequentemente, a ampliação da oferta desse tipo de atendimento estariam, assim, associadas à tendência de preparação para a escolarização? Essa obrigatoriedade seria responsável por segurar, ainda, os indicadores de matrícula na educação infantil do campo?

Enfim, são indagações construídas a partir da constatação de que o atendimento em creche parece encolher nas cidades pequenas, em relação às cidades capitais, por exemplo, e praticamente não existir nas comunidades rurais. Embora não haja estudo sobre isso, observa-se, nos indicadores do Observatório do PNE, 
que os números indicam aumento da oferta de creche nas capitais, em relação às cidades menores, e nas cidades de modo geral, em relação ao campo.

A análise da frequência das crianças em creches em todo o Brasil já foi relacionada ao trabalho materno, como destaca Fulvia Rosemberg (2015, p. 177), que observa que esta associação é "menos intensa quando se focalizam as crianças de 4 e 5 anos" e continua:

Tal associação sugere três interpretações complementares: a demanda por creche é determinada pelo trabalho materno; a oferta de vagas em creche propicia o trabalho materno; os sentidos atribuídos à Educação Infantil e as expectativas com relação a suas funções estão associadas à idade das crianças com consequências para a frequência à creche e pré-escola (2015, p. 177).

Sobre isso, é interessante analisar essa associação entre trabalho das mães do campo e a demanda por creche, bem como os sentidos que as famílias do campo atribuem à frequência dos filhos pequenos na educação infantil. Trata-se, entretanto, de uma discussão que escapa aos limites deste trabalho.

Em Ilhéus, apenas para a zona urbana, foram encontrados termos de compromisso assinados para a construção de seis creches Proinfância; para o município de Itabuna, há, no site do Simec, termos de compromisso assinados para a construção de oito creches Proinfância, para atender crianças também da zona urbana. Salienta-se que, em alguns casos, em Ilhéus e Itabuna, apesar de os termos terem sido assinados e o recurso liberado, conforme consta no site do Simec, os municípios ainda não realizaram as respectivas construções. E isso tem sido alvo de denúncias de desvios de recursos da área de educação, a exemplo da Operação Citrus, ${ }^{6}$ desencadeada pela Polícia Federal no município de Ilhéus. Vale ressaltar que, até o momento desta pesquisa, apesar de não ser objeto deste estudo, constatou-se que o município de Itabuna não fez a prestação de contas dos recursos do PAR, recebidos na gestão municipal de 2013-2016, e que o referido município está com todos os programas que dependem dos recursos desse programa federal suspensos, devido a essa falta de prestação de contas.

Assim, a falta de atendimento à educação infantil do campo, demonstrada na ausência de construção de creches para o espaço campesino, está em consonância com os dados nacionais do Censo escolar de 2016 (BRASIL, 2017), uma vez que os dados evidenciam um processo de ocultamento na educação infantil. No Brasil, das 7.016.095 matrículas na educação infantil, somente 933.444 estão concentradas no campo. De acordo com dados do IBGE (2010), mais de 3 milhões de crianças de 0 a 6 anos moram no campo; e apenas 5\% delas estão estudando. ${ }^{7}$ 
As crianças de 0 a 6 anos do campo encontram-se praticamente excluídas da educação infantil. Os indicadores nacionais evidenciam a desigualdade de acesso e a praticamente inexistência de instituições no caso do segmento de 0 a 3 anos de idade. Enquanto que na população infantil urbana a taxa de frequência à creche, de acordo com a Pesquisa Nacional por Amostra de Domicílios - PNAD 2008, era de 20,52\%, nos territórios rurais era de 6,83\%. Para as crianças de 4 e 5 anos, as porcentagens eram de 63,37 e 42,66 respectivamente. Mais especificamente nas áreas de reforma agrária, a realidade das crianças assentadas em 2005 era a seguinte: $0,1 \%$ frequentam creche familiar ou informal; $0,8 \%$ frequentam creche organizada como escola; $5,1 \%$ frequentam pré-escolas e 2,3\% frequentam classes de alfabetização. A Pesquisa Nacional da Educação na Reforma Agrária apontava ainda que apenas $3,5 \%$ das instituições educacionais do campo possuíam atendimento para crianças de 0 a 3 anos. (BRASIL, 2012, p. 4).

A Resolução CNE/CEB no 2/2008 e o Decreto Presidencial no 7.532/2010 destacam a importância de se construir escolas nas próprias comunidades rurais, principalmente para a educação infantil e os anos iniciais do ensino fundamental, evitando-se, assim, o transporte escolar para crianças pequenas; todavia, quando este for peremptoriamente necessário, deverá ser intracampo.

Nas demais ações que atendem a educação infantil no campo e o ensino fundamental, encontram-se diversos programas, conforme Tabela 4, que podem ter impactos na organização da educação infantil do campo nos municípios de Ilhéus, Itabuna e Vitória da Conquista.

Tabela 4 - Programas e projetos disponibilizados pelo governo federal para os municípios de llhéus, Itabuna e Vitória da Conquista - 2013-2016

\begin{tabular}{|c|c|c|c|c|c|c|c|c|c|c|c|c|c|c|c|c|c|c|c|c|c|c|c|c|}
\hline \multirow{3}{*}{$\begin{array}{c}\text { PROGRAMASE } \\
\text { PROJETOS }\end{array}$} & \multicolumn{6}{|c|}{2013} & \multicolumn{6}{|c|}{2014} & \multicolumn{6}{|c|}{2015} & \multicolumn{6}{|c|}{2016} \\
\hline & \multicolumn{2}{|c|}{$\mathrm{V} / \mathrm{C}$} & \multicolumn{2}{|c|}{ ITABUNA } & \multicolumn{2}{|c|}{ ILHEUS } & \multicolumn{2}{|c|}{$\mathrm{V} / \mathrm{C}$} & \multicolumn{2}{|c|}{ ITABUNA } & \multicolumn{2}{|c|}{ ILHEUS } & \multicolumn{2}{|c|}{$\mathrm{V} / \mathrm{C}$} & \multicolumn{2}{|c|}{\begin{tabular}{|l} 
ITABUNA \\
\end{tabular}} & \multicolumn{2}{|c|}{ ILHEUS } & \multicolumn{2}{|l|}{$\mathrm{V} / \mathrm{C}$} & \multicolumn{2}{|c|}{ ITABUNA } & \multicolumn{2}{|c|}{ ILHEUS } \\
\hline & CAM & $C I D$ & CAM & CID & CAM & $\mathrm{CID}$ & CAM & CID & CAM & $C I D$ & CAM & $C I D$ & CAM & CID & CAM & CID & CAM & $C I D$ & CAM & $C I D$ & CAM & $\mathrm{CID}$ & CAM & $\mathrm{CID}$ \\
\hline PDE & - & $\cdot$ & $\cdot$ & - & $\cdot$ & - & 04 & 18 & . & - & - & - & - & - & - & - & - & - & & & . & - & - & 5 \\
\hline $\begin{array}{l}\text { PDDE UNIDADE } \\
\text { EXECUTORA }\end{array}$ & 138 & 63 & - & - & - & - & 140 & 64 & - & - & - & - & 131 & 65 & - & - & - & - & 131 & 65 & - & - & 13 & 33 \\
\hline $\begin{array}{l}\text { MAIS } \\
\text { EDUCAÇÃOO }\end{array}$ & 69 & 41 & 02 & 30 & $\cdot$ & - & 72 & 41 & 03 & 39 & - & - & 13 & 15 & 03 & 38 & - & - & 23 & 15 & 01 & 23 & 13 & 28 \\
\hline $\begin{array}{l}\text { PDDE } \\
\text { ACESSIBILIDADE }\end{array}$ & 02 & 07 & - & - & $\cdot$ & & 04 & 02 & - & . & - & - & - & - & - & - & - & - & - & - & - & & 2 & - \\
\hline PDDE-AGUA & $\cdot$ & $\cdot$ & $\cdot$ & - & $\cdot$ & - & 07 & & - & - & - & - & - & - & - & - & - & & 03 & - & - & & 1 & \\
\hline PDDE-CAMPO & 35 & $\cdot$ & $\cdot$ & - & $\cdot$ & - & 34 & & - & - & - & - & - & - & - & - & & - & 02 & - & - & & 2 & \\
\hline $\begin{array}{l}\text { ATLETA NA } \\
\text { ESCOLA }\end{array}$ & 19 & 15 & $\cdot$ & - & - & - & 36 & 24 & - & - & - & - & - & - & - & - & - & - & - & - & - & & 2 & 2 \\
\hline $\begin{array}{l}\text { PDDE ESCOLA } \\
\text { SUSTENTAVEL }\end{array}$ & 11 & 11 & - & - & - & - & 03 & 04 & - & - & - & - & - & - & - & - & - & - & 06 & 06 & - & & - & - \\
\hline MAIS CULTURA & & & & & - & - & - & - & & - & . & . & - & - & - & - & . & - & - & - & - & & - & - \\
\hline $\begin{array}{l}\text { TRANSPORTE } \\
\text { ESCOLAR } \\
\text { CAMINHO DA } \\
\text { ESCOLA }\end{array}$ & - & - & 09 & - & - & - & - & - & 09 & - & - & - & 44 & - & 09 & - & - & - & 44 & & 07 & - & - & - \\
\hline $\begin{array}{l}\text { TRANSPORTE- } \\
\text { CONTRATADO }\end{array}$ & - & - & 06 & 12 & - & - & - & - & 06 & 10 & - & - & 42 & - & 06 & 10 & & - & 42 & - & 06 & 10 & 13 & - \\
\hline
\end{tabular}

Fonte: elaboração das autoras com base nos dados da pesquisa.

${ }^{*} \mathrm{~V} / \mathrm{C}=$ Vitória da Conquista. 
A Tabela 4 traz alguns dados relevantes para compreender o impacto das ações no PAR nos municípios investigados, uma vez que reflete a materialidade das ações e intenções do Estado interventor brasileiro nas escolas do campo e da cidade. Portanto, as análises das políticas educacionais do PAR no contexto da pesquisa evidenciaram a racionalidade do Estado como regulador, sob a batuta do capitalismo, presente para exercer o controle por meio das ações da NGP que descentraliza as políticas públicas. Os fenômenos depreendidos da sua relação com os entes federados sofrem influências das decisões políticas de âmbito micro e macro, porém, ficou evidente que estas devem ter o acompanhamento sistemático do MEC, bem como o monitoramento do comitê local, para que as escolas do campo possam ser melhor atendidas.

Como é possível identificar na Tabela 4, há programas para garantir o transporte escolar e o abastecimento de água nas escolas do campo. Entretanto, o atendimento ainda não cobre a demanda, como fica evidente na entrevista da coordenadora de educação infantil do município de Itabuna, que informa: "Muitas escolas do campo não dispõem de água encanada e a comunidade sempre precisa ajudar com o abastecimento" (entrevista, 2016). E, no que diz respeito ao transporte, a coordenadora enfatiza: "Das cinco escolas que eu atendo somente uma possui o transporte escolar. Nas outras, o traslado da criança das suas casas até a escola se dá via a pé ou de carona, por outros transportes até de outros municípios" (entrevista, 2016).

Tais descompassos entre a política instituída e a diversidade dos contextos das escolas do campo, especificamente no tocante à educação infantil, precisam ser compreendidos no conjunto da política educacional e na política de infância e de educação infantil nos municípios. Os dados parecem sinalizar que a educação infantil do campo, nos contextos investigados, tem ocorrido em paralelo com a política de educação básica de forma geral, sem atendimento às peculiaridades das práticas educativas para as crianças de 0 a 5 anos do campo.

\section{Algumas conclusões preliminares}

As mudanças ocorridas no Brasil, desde a década de 1970, provocaram transformações que mudaram a forma de gerir as políticas públicas e o relacionamento entre Estado e sociedade civil. Para se adequar à nova ordem mundial de cunho neoliberal, estabelecida pelos países centrais a partir da crise do Estado de bem-estar social, o Brasil reconfigurou a sua forma de gestão, pois tinha um modelo pautado na racionalidade técnica weberiana, e, a partir da década de 1980, estabeleceu um novo pacto federativo, fundamentado na colaboração entre os entes federados, cujo modelo gerencial, inspirado na iniciativa privada, passou a ser pautado na 
regulação estatal, com metas estabelecidas para alcançar maior produtividade e eficiência.

Nas políticas educacionais, essas diretrizes chegaram acompanhadas de um discurso ideológico naturalizado, por meio do qual se acreditou que é necessário modernizar para melhorar a qualidade da educação básica. Ao obedecer esses preceitos neoliberais, a política estatal se voltou para a adesão da alternativa mercadológica proposta pelo Banco Mundial e pela OCDE, de uma gestão educacional focada nos resultados e nos índices de desempenho, os quais foram incorporados no planejamento das políticas da educação por meio do PDE, mediante a assinatura, pelos entes federados, do termo de compromisso Plano de Metas Compromisso Todos pela Educação e a elaboração do PAR.

Esse novo modelo de planejamento, baseado na NGP, traz elementos importantes para a melhoria da educação básica, no que diz respeito a acompanhamento, monitoramento e recursos investidos para atingir a qualidade nesse nível educacional. Entretanto, observa-se que tais pressupostos neoliberais reduzem o papel do Estado na condução das políticas educacionais, pois este passa a ser regulador, promotor e centralizador de políticas planejadas de forma vertical, porém, com um discurso legal de que age de maneira descentralizada. Observa-se que tanto o Plano de Metas como o PAR, contraditoriamente, divulgam que primam pela descentralização das ações. Entretanto, as ações disponíveis on-line para os entes federados fazerem a adesão não dão a opção de que mudanças sejam feitas in loco, demonstrando a centralização do planejamento na esfera nacional para a implementação em âmbito municipal ou estadual, sem que estes participem do planejamento.

No que se refere às ações do PAR para as escolas do campo nos municípios pesquisados, observou-se que, no recorte temporal utilizado para coleta de dados (2013-2017), houve algumas ações implementadas por meio de vários programas educacionais, a saber: Escola Ativa, Escola da Terra, Programa Nacional do Transporte Escolar (PNATE), Programa Nacional para Alimentação Escolar (Pnae), Programa Nacional do Livro Didático (PNLD) Campo, Projovem Campo Saberes da Terra. Os dados demonstraram que, nos municípios investigados, acontecem ações que contemplam as várias dimensões do PAR apresentadas no Quadro 1. Ou seja, foram encontradas ações voltadas para a formação docente para a estrutura física das escolas que serão apresentados em outros textos. Porém, os dados evidenciaram que essas ações ainda não acontecem de maneira satisfatória, e as escolas da cidade são sempre priorizadas em detrimento das do campo. Lamentavelmente, as escolas campesinas nos municípios investigados estão sendo fechadas, e o transporte escolar tem sido utilizado em alguns casos para levar o aluno do campo para 
a cidade, negligenciando os seus direitos de estudar na sua comunidade, conforme preconiza a legislação vigente.

Especificamente sobre a educação infantil, os dados evidenciam que o pacto federativo, embora articule diferentes dimensões para o atendimento educacional, ainda não significa um avanço na cobertura do atendimento às crianças do campo e na consideração das especificidades das práticas nessa etapa da educação. Os três municípios focalizados no estudo não ampliaram a efetivação de matrículas e a construção de creches no campo, não possuem setor específico para educação infantil do campo e nem proposta pedagógica articulada com a educação do campo ou educação infantil.

Os programas voltados para a construção de creches e pré-escolas, por exemplo, não impactaram de modo particular na demanda por vaga no campo, uma vez que não foi possível observar nenhuma construção de espaços físicos para instituições de cuidado/educação coletiva em comunidades rurais. $\mathrm{O}$ atendimento é feito, majoritariamente, nas escolas de ensino fundamental, sob a alegação da baixa procura das famílias. Nessa perspectiva, pode-se indagar até que ponto a obrigatoriedade da matrícula das crianças de 4 e 5 anos tem sustentando os indicadores da oferta de educação infantil nas escolas de ensino fundamental do campo e os impactos desse "arranjo" na organização pedagógica e na continuidade da trajetória escolar.

Ao concluir este texto identificando a exiguidade da cobertura da educação infantil no campo, mesmo a partir da obrigatoriedade da pré-escola após a Emenda Constitucional no 59/2009, não se pretende ocultar tantos outros debates que perpassam a questão da oferta pública de qualidade e contextualizada. A definição de conteúdos curriculares e metodologias apropriadas às reais necessidades e aos interesses das crianças da zona rural, a organização escolar própria, incluindo adequação do calendário escolar às fases do ciclo agrícola e às condições climáticas; e a adequação à natureza do trabalho na zona rural (BRASIL, 2009) essas são apenas algumas orientações para uma ação pedagógica que leve em consideração a identidade da educação infantil do campo. Essas questões, no entanto, merecem análises posteriores no contexto deste estudo.

Também uma questão importante suscitada nesta pesquisa é a constatação da necessidade de maior articulação entre a área de educação infantil e de educação do campo na afirmação da função social e política da educação infantil. A oferta de vagas para bebês e crianças pequenas na sua localidade constitui, de antemão, um princípio de justiça social ao fazer valer o direito à educação para todas as crianças, conforme preconizado na legislação brasileira.

A articulação entre as duas áreas, nas últimas décadas, tem sido indispensável para criar um espaço para a militância por uma educação para os povos do 
campo, incluindo os mais jovens. Este espaço é visível na pesquisa, nas universidades, mas é ainda marcado por pontos de divergência em termos conceituais e orientações pedagógicas perante uma agenda neoliberal que parece colocar a educação das crianças no pacote da homogeneização. Também se pode dizer que falta ainda articulação no enfrentamento de questões comuns no que diz respeito às crianças do campo: a precariedade das instituições existentes, a precarização das condições de trabalho de professores, as más condições de transporte, a ausência de formação dos profissionais docentes, de proposta pedagógica e materiais didáticos apropriados, as classes multisseriadas, enfim, todos os problemas que perpassam a oferta existente. $\mathrm{O}$ enfrentamento desse modelo de gestão educacional atual, que esfacela a educação infantil e pode promover seu enfraquecimento, requer, cada vez mais, coesão das áreas de pesquisa, pedagogia e política.

A política educacional brasileira nos moldes do PAR faz parte de um contexto geral que serve aos propósitos do sistema capitalista, ao adotar o modelo de gestão pública que atende mais aos interesses do mercado do que dos cidadãos. E, em seu contexto singular, nesse caso os municípios pesquisados, a ressonância dessas políticas tem sido de dependência das decisões do governo federal, uma vez que os formulários preenchidos no diagnóstico das ações pelos municípios já vêm com itens preestabelecidos pelo Simec, de maneira que os entes federados não têm autonomia para fazerem proposições.

Finalmente, demarcamos que as análises sobre as políticas públicas educacionais brasileiras levantadas ao longo deste texto demonstraram que a melhoria da qualidade do ensino requer um trabalho conjunto entre os entes federados, e o planejamento coletivo é necessário. Entretanto, reconhece-se que os dados apresentados fazem parte dos fenômenos depreendidos das contradições presentes na sociedade capitalista, influenciada pelo mercado, que, no momento atual, apresenta como alternativa a centralização e o controle do Estado, o qual realiza uma descentralização de maneira coordenada, para manter os mecanismos de regulação e controle em todo o território brasileiro.

\section{Notas}

1 Os dados apresentados neste artigo são oriundos de um recorte do projeto de pesquisa intitulado: As políticas públicas educacionais do PAR em municípios da Bahia. O referido projeto é financiado pela Universidade Estadual de Santa Cruz, com bolsistas do Conselho Nacional de Desenvolvimento Científico e Tecnológico (CNPq) e da Fundação de Amparo à Pesquisa do Estado da Bahia (Fapesb).

2 PAR - Apresentação. Disponível em: <http://portal.mec.gov.br/par>. Acesso em: 16 jan. 2017.

$3 \mathrm{O}$ conceito de accountability está relacionado à obrigatoriedade de os dirigentes prestarem contas de seus atos a um órgão de controle, ao parlamento ou à própria sociedade (SANO, 2008).

4 O Simec é um portal operacional e de gestão do MEC, que trata do orçamento e monitoramento das propostas on-line do governo federal na área da educação. 
5 Disponível em: <http://portal.mec.gov.br/component/tags/tag/35008>. Acesso em: 05 fev. 2018.

6 Para conhecimento, consultar os seguintes sites: <http://agenciabrasil.ebc.com.br/geral/noticia/2017-03/ ilheus-operacao-citrus-prende-seis-pessoas-envolvidas-em-fraudes-na-prefeitura $>$; <http://www.pimenta. blog.br/2017/04/13/operacao-citrus-poe-ilheus-no-fantastico/>.

7 Disponível em: <http://www.gazetadopovo.com.br/vida-e-cidadania/criancas-do-campo-nao-tem-acesso-a-creche-b676cmri8dxma83p5onnsihxq>. Acesso em: 05 fev. 2018.

\section{Referências}

BOGDAN, Robert C.; BIKLEN, Sari Knopp. Investigação qualitativa em educação. São Paulo: Vozes, 1982.

BRASIL. Constituição da República Federativa do Brasil de 1988. Brasília, DF: Senado, 1988.

Instituto Nacional de Estudos e Pesquisas Educacionais Anísio Teixeira. Censo Escolar da Educação Básica, 2016 - notas estatísticas. Brasília, DF: 2017. Disponível em: <https://www. google.com.br/search?hl=pt-PT\&ei=HybkW4HHC8LTwgTOvIfoD>. Acesso em: 12 dez. 2017.

Lei $\mathrm{n}^{\circ}$ 9.394, de 20 de dezembro de 1996. Estabelece as diretrizes e bases da educação nacional. Brasília, DF, 1996.

. Ministério da Educação. Secretaria de Educação Básica. Diretrizes Curriculares Nacionais para a Educação Infantil. Brasília, DF: MEC/SEB, 2009.

Parâmetros Básicos de Infraestrutura para Instituições de Educação Infantil. Brasília, DF: MEC, SEB, 2006a.

$2006 \mathrm{~b}$.

Parâmetros Nacionais de Qualidade para a Educação Infantil. Brasília, DF: MEC/SEB,

Decreto $\mathrm{n}^{\circ}$ 6.094, de 24 de abril de 2007. Dispõe sobre a implementação do Plano de Metas Compromisso Todos pela Educação. Diário Oficial da União, Poder Executivo, Brasília, DF, 2007a. Disponível em: <http://www.planalto.gov.br/ccivil_03/_Ato2007-2010/2007/Decreto/ D6094.htm>. Acesso em: 15 jan. 2017.

Ministério da Educação. Universidade Federal do Rio Grande do Sul. Pesquisa nacional caracterização das práticas educativas com crianças de 0 a 6 anos de idade residentes em área rural. Brasília, DF; Porto Alegre, RS: MEC/Ufrgs, 2012.

Resolução CNE/CEB no 1 , de 03 de abril de 2002. Diretrizes Operacionais para a Educação Básica nas Escolas do Campo. Brasília, DF: CNE/CEB, 2002.

Resolução Complementar CNE/CEB nº 2, de 28 de abril de 2008. Diretrizes complementares, normas e princípios para o desenvolvimento de políticas públicas de atendimento da Educação Básica do Campo. Brasília, DF: CNE/CEB, 2008. Disponível em: <http://portal.mec. gov.br/arquivos/pdf/resolucao_2.pdf> Acesso em: 15 fev. 2017.

Decreto no 7.352, de 04 de novembro de 2010. Institui o Programa Nacional de Educação na Reforma Agrária. Brasília, DF, 2010a.

Resolução no 4, de 13 de julho de 2010. Define Diretrizes Curriculares Nacionais Gerais para a Educação Básica. Brasília, DF: CNE/CEB, 2010b. 
. Observatório do Plano Nacional de Educação. 2017. Disponível em: <http://www.observatoriodopne.org.br>. Acesso em: 13 jun. 2018.

CABRAL NETO, Antônio. Gerencialismo e gestão educacional: cenários, princípios e estratégias. In: FRANÇA, Magna; BEZERRA, Maura costa (Org.). Política educacional: gestão e qualidade do ensino. Brasília, DF: Liber Livro, 2009. p. 1-346.

CASTRO, Alda Maria Duarte Araújo; TERTO, Daniela Cunha; BARBOSA, Maria Wanessa do Nascimento. A nova gestão pública e os desdobramentos para os planos e programas governamentais. Campinas, SP: Mercado de Letras, 2016. (Série Educação Geral, Educação Superior e Formação Continuada do Educador).

HADDAD, Fernando. O Plano de Desenvolvimento da Educação: razões, princípios e programas. Brasília, DF: MEC/Inep, 2008.

INSTITUTO BRASILEIRO DE GEOGRAFIA E ESTATÍSTICA. Censo Demográfico 2010. Rio de Janeiro: IBGE, 2010.

KOSIK, Karel. Dialética do concreto. 6. ed. Trad. Célia Neves e Alderico Toríbio. Rio de Janeiro: Paz e Terra, 1997.

LIMA, Paulo Gomes et al. Políticas educacionais, participação e gestão democrática da escola na contemporaneidade brasileira. Ensaio, Belo Horizonte, v. 14, n. 1, p. 51-64, jan./abr. 2012.

MARX, Karl. Manuscritos econômico-filosóficos. Trad. Jesus Ranieri. São Paulo: Boitempo, 1982.

MÉSZÁROS, István. El desafío y la carga del tiempo histórico: el socialismo del siglo XXI. Valencia: Vadell Hermanos/CLACSO, 2011.

ROSEMBERG, Fulvia. A cidadania dos bebês e os direitos de pais e mães trabalhadoras. In: FINCO, Daniela et al. Creche e feminismo: desafios atuais para uma educação descolonizadora. São Paulo: Fundação Carlos Chaga, 2015. p. 163-184.

ROSEMBERG, Fulvia; ARTES, Amélia. O rural e o urbano na oferta de educação para crianças de até 6 anos. In: BARBOSA, Maria Carmem Silveira et al. Oferta e demanda de educação infantil no campo. Porto Alegre: Evangraf, 2012. p. 7-331.

SANO, Hironobu. Articulação horizontal no federalismo brasileiro. Os conselhos de secretários estaduais. Tese (Doutorado em Administração Pública e Governo) - Escola de Administração de Empresas de São Paulo, Fundação Getúlio Vargas, São Paulo, 2008.

SAVIANI, Dermeval. O plano de desenvolvimento da educação: análise do projeto do MEC. $E d u$ cação e Sociedade, Campinas, v. 28, n. 100, p. 1231-1255, out. 2007. Disponível em: <http://www. scielo.br/pdf/es/v28n100/a2728100.pdf>. Acesso em: 16 jun. 2018.

SILVA, Maria Vieira. Trabalho docente na américa latina: desafios ao campo da pesquisa e às políticas educacionais. Revista Educação e Políticas em Debate, Uberlândia, v. 2, n. 2, p. 277-303, jul./dez. 2012.

SILVA, Maria do Socorro Araújo; CRUZ, Rosana Evangelista da. O Plano de Ações Articuladas: desafios para a gestão educacional. Revista Fundamentos, Teresina, v. 2, n. 2, 2015.

VITÓRIA DA CONQUISTA. Secretaria Municipal da Educação. Setor de Legalização e Estatística. Vitória da Conquista: Secretaria Municipal da Educação, 2017. 